DOI 10.37882/2223-2982.2021.04-2.28

\title{
ЛИНГВОКУЛЬТУРОЛОГИЧЕСКИЕ ХАРАКТЕРИСТИКИ И СПЕЦИФИКА АВСТРАЛИЙСКОГО ВАРИАНТА АНГЛИЙСКОГО ЯЗЫКА
}

\section{LINGUOCULTURAL CHARACTERISTICS AND SPECIFICITY OF THE AUSTRALIAN VERSION OF THE ENGLISH LANGUAGE \\ E. Razumovskaya I. Kireeva}

Summary: The relevance of this work is due to linguistic and cultural factors: the great interest of linguists in the variability of the English language, geopolitical interest in the dynamically developing Australia, consideration of the Australian version of the English language allows you to plunge into the Australian culture and social sphere of life of Australian civil society.

The aim of the research is to summarize the linguocultural characteristics and study the specifics of the Australian version of the English language. The article was prepared on the basis of scientific and practical analysis of domestic and foreign literature on the research problem. The article discusses in detail the linguocultural characteristics and special features of the modern Australian version of the English language. The role of the use of the Australian version of the English language in the development of the country's linguistic culture and the comprehensive expansion of the lexical stock of the English language as a whole is analyzed. A brief excursion into the history of the emergence of the Australian version of the English language is carried out, its cultural and linguistic significance in the linguistic picture of English-speaking countries is indicated. The results of the research in the article allow us to say that the Australian version of the English language appeared as a result of the evolution of dialects spoken by the first inhabitants of Australia.

Keywords: linguocultural characteristics, specificity of the Australian version of the English language, Australian accent, even intonation, soft tone, evolution of dialects.

\author{
Разумовская Елена Александровна \\ К.С.н., доцент, Институт международного права и \\ экономики им. А.С. Грибоедова \\ razumovskaya@mail.ru \\ Киреева Ирина Анатольевна \\ K.n.н., дочент, АНОВО «Московский международный \\ университет» \\ arina_68@bk.ru
}

Аннотация: Актуальность данной работы обусловлена лингвокультурологическими факторами: огромным интересом лингвистов к вариативности английского языка, геополитическим интересом к динамично развивающейся Австралии, рассмотрение австралийского варианта английского языка позволяет окунуться в австралийскую культуру и социальную сферу жизнедеятельности гражданского общества Австралии.

Цель исследования состоит в обобщении лингвокультурологических характеристик и изучении специфики австралийского варианта английского языка. Статья подготовлена на основе научно - практического анализа отечественной и зарубежной литературы по проблеме исследования. В статье подробно рассматриваются лигвокультурологическая характеристика и особые черты современного австралийского варианта английского языка. Анализируется роль использования австралийского варианта английского языка в освоении лингвокультуры страны и комплексного расширения лексического запаса английского языка в целом. Проведен краткий экскурс в историю возникновения австралийского варианта английского языка, обозначено его культурологическое и лингвистическое значение в языковой картине англоязычных стран. Итоги исследования в статье позволяют говорить 0 том, что австралийский вариант английского языка появился в результате эволюции диалектов, на которых говорили первые жители Австралии.

Ключевые слова: лингвокультурологическая характеристика, специфика австралийского варианта английского языка, австралийский акцент, ровная интонация, мягкий тон, эволюция диалектов.
$\Pi$ роцесс развития нации в Австралии проходил не путем трансформации всех культур, развивающихся на территории данной страны, кроме доминирующей, а через принцип равенства лингвокультур и языковых групп всех населяющих континент народов. Австралийский вариант английского языка является лингвистическим маркером национальной идентификации народа и самобытности культуры Австралии. Современная языковая политика в Австралии обеспечивает государственную поддержку всем языковым группам, функционирующим в стране. Заметим, что австралийский вариант английского языка - родной язык большей части населения Австралии, один из основных вариан- тов английского языка, который используется на территории данного государства.

Проблеме изучения сущностных характеристик и особенностей австралийского варианта английского языка посвящены отдельные труды отечественных ученых (Ю.А. Акопян, Г.Б. Антрушиной, О.В. Афанасьевой, Н.Н. Морозовой, Л.И. Апполоновой, Г.Н. Бабич, В.Д. Беленькой, В.В. Ощепковой, А.С. Петриковской, С.Б. Прядко и др.).

Например, в исследовании Ю.А. Акопян представлены лексико-семантические особенности австралийско- 
го варианта английского языка, на материале австралийской поэзии [2]. Г.Б. Антрушина, О.В. Афанасьева и Н.Н. Морозова рассматривают основные положения лексикологии английского языка, в частности, этимологический состав и стилевые слои словарного состава английского языка, что особенно важно для нашего исследования [3].

Л.И. Апполонова в своей работе описывает особенности лексико-семантической системы австралийского варианта английского языка. По мнению Л.И. Апполоновой, «Австралийский вариант английского языка по своему происхождению является так называемым «городским» языком, поскольку первые переселенцы-носители языка были в основном городскими жителями...» [4, с.18]. Г.Н. Бабич уделяет особое внимание проблемам слова в лексикологии английского языка [5].

Особый интерес для нашего исследования в статье представляют очерки топонимии Австралии В.Д. Беленькой, где рассматривается структура англоязычных названий [6]. Лингвокультура Великобритании, США, Австралии и других англоязычных стран представлена в работе В.В. Ощепковой [7]. А.С. Петриковской разработано послесловие к лингвострановедческому словарю Австралия и Новая Зеландия [8]. Исследование С.Б. Прядко знакомит нас с культурным компонентом значения слова в лингвострановедческой лексике австралийского варианта английского языка на примере аборигенных заимствований [9].

Анализ вышеуказанных источников позволяет сделать вывод о том, что аспекты решения проблемы нашего исследования рассматривались очень давно и не учитывали стремительно развивающиеся языковые новинки австралийского варианта английского языка.

В качестве объекта нашего исследования в статье выступают австралийский национальный онлайн словарь и словарь австралийского слэнга $[1,10]$.

Далее мы обобщим лингвокультурологические характеристики и параметры специфики австралийского варианта английского языка и представим их более подробно.

Австралийский вариант английского языка является одним из главных географических вариантов английского языка. Он существует и используется в обиходе наряду с британским, американским, шотландским и новозеландским. В некоторых сферах общения австралийский вариант английского языка схож с британским вариантом, особенно в плане грамматического оформления речи и текста на английском языке, принятом в Австралии. Отличительные признаки австралийского варианта от других вариантов проявляются, прежде всего, в фонетике. Однако лексические и фразеологические особенности также характеризуются особой спецификой. В современном австралийском варианте английского языка часто используются страноведческие реалии, которые применяются в другом орфографическом виде.

Австралийский вариант английского языка чаще всего несет в себе черты британского и американского вариантов английского языка. Кроме того, проблема рассмотрения трех вариантов английского языка осложняется наличием трех различных типов произношения. Однако это разделение не усложняет процесс межкультурной коммуникации. Рассмотрев особенности австралийского варианта английского языка, можно сделать вывод, что классический английский язык претерпел значительные изменения в результате колониальной политики Великобритании и формирования в этой связи новых этносов и соответствующих культурных различий между ними. Общеизвестно, что первые поселенцы Австралии являлись носителями просторечий и диалектов. На современном этапе развития лингвокульторологии Австралии достаточно сильное влияние оказал американский вариант английского языка.

На основании рассмотренного нами материала можно сделать вывод, что большая часть австралийского лексического состава совпадает со словарным составом британского варианта. Австралийские слова присутствуют в наиболее важных областях для австралийцев: географические обозначения, развитие сельского хозяйства, добыча полезных ископаемых, интеграция инокультур и другие, характерные для Австралии сферы деятельности человека.

Рассмотрим современную специфику австралийского варианта английского языка более детально.

Британский и американский варианты английского языка отличает, прежде всего, интонация. Собеседник может говорить то громче, то тише, поднимать и опускать тембр, делать паузы и подчеркивать отдельные слова. В австралийском варианте английского языка сохраняется ровный тон, обеспечивая непрерывный поток речи. Австралийская речь также отличается мягким тоном, когда гласные произносятся более мягко. Это возможно услышать в аудиозаписи. Чтобы подстроиться под этот тон, необходимо слушать живую речь.

Отличительными особенностями австралийского варианта английского языка являются определенные замены в речи и на письме, а именно:

- оі вместо ai (write - wroite, bike - boike);

- aі вместо a (cat - kayet, bad - bayed);

- смягченная «а», когда в отдельных регионах «а» 
звучит намного мягче, как «еh» (hat - heht, bat beht). При этом смягчение идет перед мягкими согласными, зачастую это буква t. А буквы d, b, g и так далее считаются звонкими, поэтому перед ними гласные не смягчаются. И это правило касается только слов, где буква дает звук «э» (то есть part, darts сюда не относятся).;

- пауза перед t в конце слова (righ-t, migh-t);

- ah вместо er (river - rivah, letter - lettah);

- n' вместо ng (running - runnin', flying - flyin'). Буква «g» на конце слова после $\mathrm{n}$ не читается никак. Просто необходимо представить, что ее не существует.

На примере мини-словаря возможно более четко увидеть фонетическую и орфографическую специфику австралийского варианта английского языка:

Arvo - afternoon - вечер;

Brolly - umbrella - зонтик;

Crook - sick - больной;

Dead horse - ketchup - кетчуп;

Esky - small icebox - мини-холодильник;
Festy - dirty - грязный;

Fix up - pay money back - вернуть долг;

Flat chat - very busy - очень занятой;

Yakka - work - работа;

Nah-yeah - yes - да;

Yeah-Nah - no - нет;

Scrap - fight - драка;

Servo - petrol station - заправка;

Smoko - cigarette break - перекур;

Sparky - electrician - электрик;

Stoked - happy - счастливый;

Thongs - flops - шлепки;

Top bloke - good guy - хороший парень.

Таким образом, рассмотрев лингвокультурологические характеристики и специфику австралийского варианта английского языка, можно сделать вывод, что особенность его лексического состава создается присутствием в нем австрализмов содержащих в своем значении собственный лингвокультурный код национального многообразия и идентичности нации англоязычной Австралии.

\section{ЛИТЕРАТУРА}

1. Австралийский национальный онлайн словарь. http://www.macquariedictionary.com.au/(Дата обращения: 08.03.2021).

2. Акопян Ю.А. Лексико-семантические особенности австралийского варианта английского языка: на материале австралийской поэзии: дисс. . . к. филолог. наук /Ю.А. Акопян. - Москва, 2003.

3. Антрушина Г.Б., Афанасьева О.В., Морозова Н.Н. Лексикология английского языка: учеб. пособие для студентов. - М.: «Дрофа», 1999.

4. Аполлонова Л.И. Особенности лексико-семантической системы австралийского варианта английского языка: дисс. .. канд. филолог. наук. /Л.И. Апполонова. - Ленинград, 1991.

5. Бабич Г.Н. Лексикология английского языка. - Екатеринбург-Москва: Уральское издательство «Большая медведица», 2006.

6. Беленькая В.Д. Очерки топонимии Австралии. Очерк 2. Структура англоязычных названий. // Вестник Московского университета. - М., $1973,1$.

7. Ощепкова В.В. Язык и культура Великобритании, США, Канады, Австралии, Новой Зеландии. - М./СПб.: «Глосса/Каро», 2004.

8. Петриковская А.С. Послесловие к лингвострановедческому словарю Австралия и Новая Зеландия. -М.: «Русский язык», 1998.

9. Прядко С.Б. Язык и культура: культурный компонент значения слова в лингвострановедческой лексике австралийского варианта английского языка (на примере аборигенных заимствований): дисс. .. канд. филолог. наук. /С.Б. Прядко. - Москва, 1999.

10. Словарь австралийского слэнга. http://www.australia.ru/page/aussie_slang/b.html/ (Дата обращения: 08.03.2021).

( Р Разумовская Елена Александровна (razumovskaya@mail.ru), Киреева Ирина Анатольевна (arina_68@bk.ru). Журнал «Современная наука: актуальные проблемы теории и практики» 